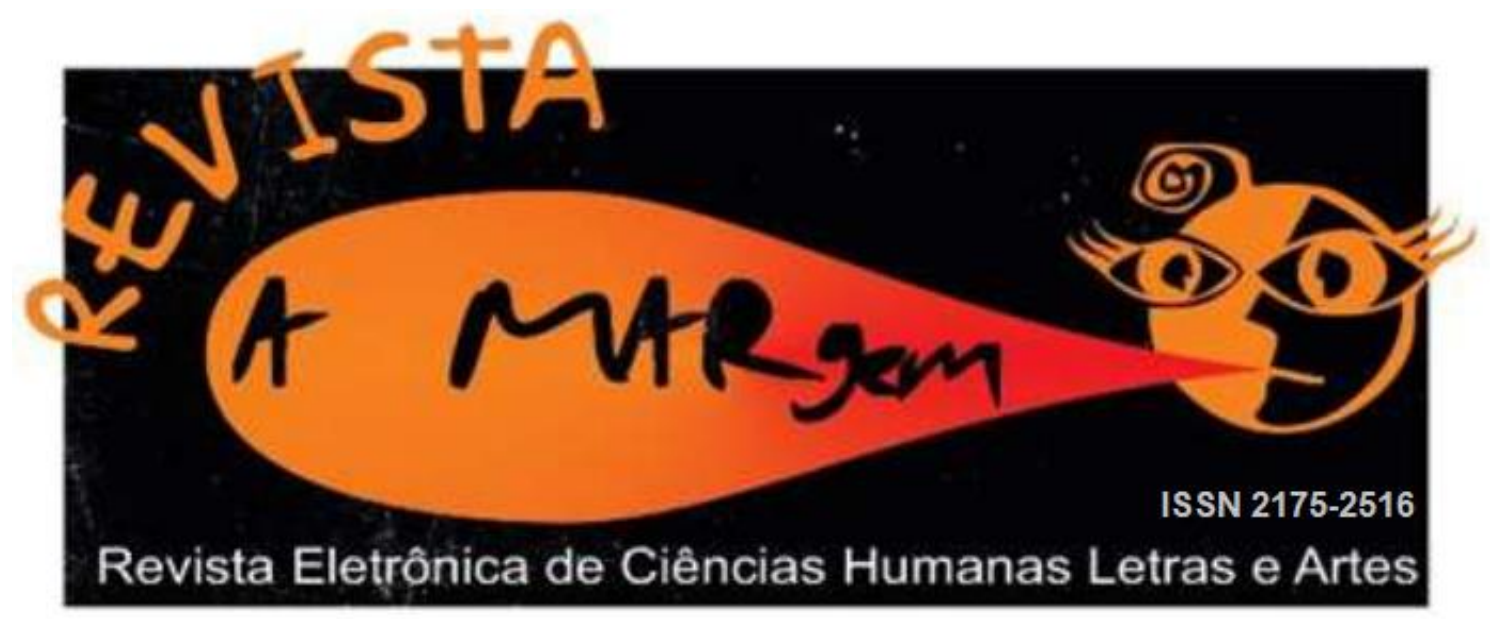

\title{
ENTRE A CELA E A CENA: DESAFIOS DE UMA PEDAGOGIA TEATRAL E CARCERÁRIA
}

\section{Laís Jacques Marques Universidade Federal de Santa Maria (UFSM) \\ Marcia Berselli Universidade Federal de Santa Maria (UFSM)}

Resumo: O presente artigo visa analisar e problematizar relatos de experiências vivenciadas com Teatro em ambiente carcerário. Primeiramente, relato a vivência que tive como condutora de oficinas no CASE - SM, e posteriormente, analiso o trabalho de Vicente Concílio com internos (as) em presídios nacionais, mas principalmente na Penitenciária Feminina de São Paulo. Concluo relacionando as práticas e questionando o que pode a arte da cena colaborar, em que sentido e para quê, em locais não convencionais, como penitenciárias.

Palavras-chave: teatro, penitenciária, adolescentes, desvios.

\section{BETWEEN PRISON CELL AND SCENE: CHALLENGES OF A THEATER AND CARCERARY PEDAGOGY}

Abstract: This article aims to analyze and problematize reports of experiences with Theater in prisons. Firstly, I describe the experience that I had as a conductor of workshops at CASE - SM, and later, I analyze the work of Vicente Concílio with inmates in Brazilian prisons, but mainly at the Penitenciária Feminina de São Paulo. I conclude by relating the practices and questioning what the art of the scene can collaborate, in what sense and for what, in unconventional places, such as penitentiaries.

Keywords: theater, penitentiary, teenagers, deviance.

O presente artigo visa analisar e problematizar relatos de experiências vivenciadas com Teatro em ambiente carcerário. A partir de experiências como condutora de oficinas em espaços de restrição de liberdade, busca-se observar e analisar quais as possibilidades 
do desenvolvimento de práticas teatrais com jovens que vivem nesses espaços. Nesse sentido, uma contradição inicial marca as práticas a serem analisadas. $\mathrm{O}$ teatro, arte que tem em sua base a exposição corporal, necessitaria da confiança e liberdade de expressão. Mas, o espaço em questão tem em seu cerne a perspectiva coercitiva.

De modo a analisar essas complexas tramas que envolvem liberdade e coerção, como fonte teórica e prática, conto com os brasileiros Augusto Boal e sua obra Teatro do Oprimido (1977), Paulo Freire, com a Pedagogia do Oprimido (1987) e a Pedagogia da Autonomia (2016) e o professor e pesquisador Vicente Concílio, em seu trabalho com presidiários (as) intitulado Teatro e prisão: dilemas da liberdade artística (2008). Em âmbito mundial e, principalmente, analítico de sistema carcerário, o francês Michel Foucault e sua obra Vigiar e Punir (2014) solidifica e amplia o histórico do sistema penal. Além dele, o sociólogo estadunidense preocupado com conceitos como o de desvio, Howard Becker e sua obra Outsiders (2008), me contempla quando direciona seu discurso para minorias presentes na sociedade contemporânea. Viso, com eles, ampliar o debate e ir além dos relatos de experiência, refletindo assim sobre o papel do educador de arte nesse espaço de vigilância constante que é o presídio.

\section{Passos curtos, algemados pelos pés}

Parto de minha experiência como ministrante de oficina de Teatro do Oprimido no CASE (Centro de Acolhimento Sócio-Educativo), que fica dentro das mediações do DEASE (Departamento de Acolhimento Sócio-Educativo), órgão maior. O local serve como abrigo para menores infratores de gênero masculino - dos 12 aos 21 anos - que sofreram medidas punitivas judiciais e estão respondendo pelos delitos em regime fechado.

Sediado na cidade de Santa Maria, no interior do estado do Rio Grande do Sul, o CASE possui escola e oficinas de diversas áreas do conhecimento (de jogos de mesa e cinema, à culinária e artesanato), além de dormitórios e refeitório no próprio local. Atualmente conta com 77 detentos de variadas idades e mais de 100 funcionário. A proposta que conduzi foi desenvolvida vinculada a um projeto de extensão da Universidade Federal de Santa Maria (UFSM). Através de edital lançado pela UFSM que eu, acadêmica do Curso de Licenciatura em Teatro, graduada em Artes Cênicas e 
atualmente mestranda da Universidade do Estado de Santa Catarina, tive contato com o ambiente CASE e com os jovens que passaram a participar da oficina de teatro. ${ }^{1}$

\section{Percepções}

Toda prática de teatro inicia muito antes da entrada do professor - oficineira, neste caso - na sala de aula. Ao refletir e esboçar os primeiros traços do planejamento da prática que se intenciona desenvolver, o professor já está colocando em movimento as engrenagens da experiência de ensino-aprendizagem. Ao elaborar o plano, o professor projeta algo de acordo com um contexto específico, envolvendo, nesse movimento, não só as pessoas que participarão da prática, mas o espaço em que a mesma será desenvolvida. Nesse sentido, um primeiro desafio estava posto em relação ao espaço físico. Seria preciso reconhecer o espaço antes de projetar o que ali seria desenvolvido. Que espaço é esse, do cárcere, do recolhimento dos corpos?

\section{Primeira cena: olhar para o espaço}

O local é cercado por arame farpado. Seguranças e policiais revezam a vigilância na verificação de entrada e saída dos oficineiros. Nada deve entrar e muito menos sair dali. As salas cedidas para as propostas são pequenas, cerca de $5 \mathrm{~m} \times 5 \mathrm{~m}^{2}$, porém, trabalhamos com no máximo seis alunos por aula, o que permitiu suficiente mobilidade. Com televisor, rádio, caixas de som e paredes coloridas, a sala é bastante arejada e remete às salas de aula convencionais dos municípios com verbas recebidas em dia. O que diferencia (e talvez limite alguns trabalhos) é sempre o sistema acirrado de vigilância a que o centro deve aderir.

Dos jovens, nos apresentaram (nas palavras da assistente social do local) os “melhores", os que mais se adequam às medidas sócio-educativas. Evidentemente algo a se refletir: de que maneira a instituição criou esta classificação? Adiante discorreremos sobre.

O trabalho, à primeira vista rígido (no que concerne à vigilância constante em que vivem os jovens), se mostrou afetuoso em certo ponto por parte da administração,

\footnotetext{
${ }^{1} \mathrm{O}$ projeto Teatro e menores infratores, parte de uma iniciativa da PRE (Pró-Reitoria de Extensão) juntamente ao CASE e ao CASEME. O segundo se refere ao acolhimento de menores infratores que possuem penalidade leve e as cumprem em regime semi-aberto. Sem restrição de gênero, as e os reclusos têm permissão para saída do local, desde que acompanhados pelos agentes de vigilância. O projeto foi coordenado pela $\operatorname{Prof}^{\mathrm{a}} \mathrm{Dr}^{\mathrm{a}}$ Raquel Guerra (docente na UFSM).
} 
psicólogas e assistentes sociais que lá atuam. Ouvimos relatos emocionados, palavras da diretora do local, que diz "quanto mais gostamos dos reclusos, mais gostaríamos que saíssem daqui e que não retornassem". Penso que assumir seu afeto pelos jovens, e de certa forma desejar um futuro próspero para eles, solidifique ou potencialize a qualidade do trabalho das e dos funcionários. Enquanto profissionais que compreendem as limitações de liberdade como medida de segurança social, suas tarefas não se limitam ao permitir pensamento crítico, mas suscitá-lo, potencializá-lo, torná-lo ferramenta de transformação. Para além das máscaras sociais que todos nós, em alguma medida, vestimos, me interessou entender como, nessa relação hierárquica, de poder e vigilância constantes, inserir afeto à relação. É sabido que a afeição e o carinho na relação educando e educador, é vista no contexto freireano como metodologia de aproximação da educação e do mundo. Aqui, recorro às palavras de Paulo Freire para demonstrar uma possível leitura do que observei em visitas:

[...] uma das tarefas mais importantes da prática educativo-crítica é proporcionar as condições em que os educandos em suas relações uns com os outros e de todos com o professor ou a professora ensaiam a experiência profunda de assumir-se. Assumir-se como ser social e histórico, como ser pensante, comunicante, transformador, criador, realizador de sonhos, capaz de ter raiva porque capaz de amar. (FREIRE, 2016, p. 42)

Recorro a Freire para devolver uma questão à administração do centro: seriam eles, os reclusos, sujeitos de suas próprias histórias, seres sociais assumidos? Ou, considerando que vivem em um sistema de vigilância e coerção constantes, estariam os jovens de alguma forma assumindo um papel de obediência para tornarem sua estadia no centro menos agressiva?

De posse de algumas informações sobre o espaço físico, o segundo movimento, ainda antes do planejamento, diz respeito à compreensão dos objetivos daquele espaço. Para que os jovens estão ali?

\section{Segunda cena: descobrir as intenções}

No que concerne aos valores e à missão do CASE para com os menores internos em suas mediações, recolhi dados disponíveis no site do órgão, onde lê-se

Missão: executar o programa estadual de medidas socioeducativas de internação e semiliberdade, oportunizando a reinserção social dos adolescentes, em parceria com a sociedade. Valores: compromisso com a socioeducação e com a instituição - engajamento com 
responsabilidade e determinação em todas as atividades socioeducativas. Refletir a transparência das ações em prol do bem comum e da instituição que representa; práticas restaurativas empenhar-se com o diálogo, a inovação e, com o incentivo à reflexão; ética - Consciência individual e prática institucional dos princípios que fundamentam a conduta íntegra e educativa; respeito - tratamento às pessoas com urbanidade, civilidade, atenção e igualdade, sem distinção de qualquer natureza; responsabilidade - Com seriedade e probidade na forma de agir, e também com o compromisso de sua missão: reinserção social; e segurança - Buscar a estabilidade nos serviços oferecidos em um ambiente favorável à integridade física e psíquica das pessoas. Visão: até 2020, alcançar níveis superiores de ressocialização dos adolescentes internos na FASE. ${ }^{2}$

Penso que o trabalho com teatro se adeque ao que compreendo como o objetivo das práticas restaurativas. Principalmente quando deixam estabelecido que a prática se refere à ampliação de diálogo e ao estímulo dos jovens a refletir sobre sua atual condição. O ensino de teatro propõe, além de inserir no arsenal de linguagens dos jovens uma nova possibilidade de comunicação - a corporal -, a promoção do pensamento crítico não só nas atividades que realizam em aulas, mas na inserção do que refletem suas ações num contexto amplo, para além dos jogos teatrais. Nos interessa encontrar o que e como agregar do que praticamos nos exercícios ao cotidiano dos jovens.

A partir disso, reconhecendo espaço e objetivos da instituição, trabalhei com a questão que me cabe, enquanto ser interessada pelo teatro em espaços não convencionais e de difícil acesso, mas, principalmente, enquanto artista e futura docente. Porém, ainda, antes do planejamento das atividades, antes de definir quais as práticas e propostas eu desenvolveria com um grupo - ainda desconhecido - de jovens com restrição de liberdade, foi necessário reconhecer os meus objetivos em relação às práticas cênicas prestes a serem iniciadas. Meu objetivo com o trabalho, na época, era mobilizar conhecimentos corpóreos, sensíveis e subjetivos, ao mesmo tempo explicitar aos menores suas capacidades no que se refere à elaboração de pensamento crítico e criativo. Gostaria que saíssem das aulas questionando não somente suas ações, mas as regras em que estão inseridas estas ações, e o contexto que os aprisiona, os limita, mas, em certo sentido, também pode ser promotor de potência.

\section{Atrito entre os objetivos}

\footnotetext{
2 Disponível em <http://www.fase.rs.gov.br/wp/missao-e-valores/>. Acesso em 21 maio, 2019. A terminologia 'FASE' refere-se ao antigo nome utilizado por Departamentos de Acolhimento Sócioeducativos (DEASE). Hoje, a maioria dos DEASE'S já aderiu chamar suas Fundações (FASE) de Centros, tornando-os CASE.
} 
Ao verificar meus objetivos, observei um tensionamento entre o contexto no qual desenvolveríamos as práticas e aquilo que eu buscava proporcionar aos jovens. Meu desejo centrava-se em promover um outro espaço, em que a arte teatral, capaz de movimentar discussões em corpos jovens já tão mecânicos e obedientes, nos levasse a explorar possibilidades lúdicas e sensíveis, criando universos ficcionais e estimulando posicionamentos. Seria possível que o teatro, fundado na exposição dos participantes, encontrasse solo fértil naquele ambiente de repressão?

O questionamento quanto aos motivos de cada um estar ali não nos interessa. Aqui, o que nos importa é a modificação que o centro já tem realizado na visão de mundo de cada um, e a mudança efetiva de postura dos adolescentes perante os dilemas presentes na vida particular, para fora do centro. O que farão após saírem? Como enfrentarão o desemprego? E a criminalização? O preconceito? São respostas que eles ainda não possuem (e nós tampouco), mas estamos dispostas a ajudá-los a construir uma perspectiva otimista das situações.

\section{Terceira cena: Planejamento}

Para Jorge Larrosa (2004), quando o professor procede à escolha do texto a ser lido na aula, ele se coloca em ação de preparar um presente ao estudante, pois escolher algo a ser realizado com o outro já seria um início dessa atividade. Escolher o texto, assim, seria escolher algo para presentear o outro, uma conexão afetiva entre professor e estudante que se dá antes do encontro na sala de aula.

Da mesma forma que aquele que remete um presente ou uma carta, o professor sempre está um pouco preocupado para saber se seu presente será aceito, se sua carta será bem recebida e merecerá alguma resposta. Uma vez que só se presenteia o que se ama, o professor gostaria que seu amor fosse também amado por aqueles aos quais ele o remete. E uma vez que uma carta é como uma parte de nós mesmos que remetemos aos que amamos, esperando resposta, o professor gostaria que essa parte de si mesmo, que dá a ler, também despertasse o amor dos que a receberão e suscitasse suas respostas. (LARROSA, 2004, p. 140)

Assim entendemos a preparação da aula de teatro. Ao escolher as propostas, o professor já se coloca em estado de jogo na expectativa da resposta - sempre apenas uma visão, sempre apenas uma possibilidade, sempre menos do que efetivamente acontecerá no encontro - daquele a quem a prática se destina. Enquanto algo que só se concretiza no 
convívio, o teatro é apenas ideia até o encontro dos corpos na sala de aula. Mas o professor já se coloca em ação desde o primeiro esboço. Começa a aula antes mesmo da troca de olhares. Quando chega na sala, quando os corpos ocupam um mesmo espaço físico, o planejamento é colocado à prova, o professor responsável tanto quanto os participantes por desembrulhar o presente e descobrir o que dele provoca encanto.

\section{O teatro se concretiza: o lúdico sobrevive ao olhar vigilante?}

Para as primeiras aulas tomamos os princípios de Augusto Boal ${ }^{3}$, com o trabalho voltado para todas as pessoas interessadas no fazer teatral, no querer dizer algo através do teatro. Ele nos afirma que partir da consciência corporal de cada um é o caminho ideal para facilitar o diálogo artístico:

Podemos mesmo afirmar que a primeira palavra do vocabulário teatral é o corpo humano, principalmente fonte de som e movimento. Por isso, para que se possa dominar os meios de produção teatral, deve-se primeiramente conhecer o próprio corpo, para poder depois torná-lo mais expressivo. Só depois de conhecer o próprio corpo e ser capaz de torná-lo mais expressivo, o 'espectador' estará habilitado a praticar práticas teatrais que, por etapas, ajudem-no a libertá-lo de sua condição de 'espectador' e assumir a de 'ator', deixando de ser objeto e passando a ser sujeito, convertendo-se de testemunha em protagonista. (BOAL, 1977 , p. 131, grifos do autor)

Assumir o papel de protagonista e agente de suas ações, responsáveis por elas e por suas consequências, era o que visava. Busquei desenvolver nos participantes a agência e responsabilidade sobre suas ações. Aderi a exercícios e jogos que estimulassem os adolescentes a se moverem de modo distinto do cotidiano, descobrindo novos sons e ritmos para o andar, sentar, correr, pular etc. Visei, com isso, demonstrar que somos fonte de diversas facetas e que cada situação teatral pode e deve recorrer a esse arsenal. O desafio maior era o de como trabalhar o conhecer-se em ambiente vigiado, objeto de constante censura e repressão. Voltando as sugestões e colaborações de Boal, segui:

Existe uma enorme quantidade de exercícios que se podem praticar, tendo todos, como primeiro objetivo, fazer com que o participante se torne cada vez mais consciente do seu corpo, de suas possibilidades corporais, e das deformações que o seu corpo sofre devido ao tipo de trabalho que realiza. (BOAL, 1977, p. 133)

\footnotetext{
${ }^{3}$ Augusto Boal (1931 - 2009) foi dramaturgo, diretor e ensaísta brasileiro. Seu trabalho de maior renome se intitula Teatro do Oprimido. É com os princípios deste, subsidiado de demais referências teatrais, que trabalhei.
} 
Como sabemos, é natural que nossos corpos se modelem de acordo com o uso que necessitamos fazer dele. Se repetirmos por diversos anos uma atividade, o corpo compreenderá modos práticos de realizar a atividade, e não buscará - se não receber estímulos para isso - modos distintos de realizá-la. Estes movimentos, reflexos das atividades que exercemos, revelam padrões de comportamento e de respostas, e quase falam sobre os modos com que agimos socialmente. Aqui, sinto necessidade de recorrer a Foucault (2008) e a sua obra Vigiar e Punir.

Foucault (2008) alerta para a docilidade dos corpos, dentro de uma estrutura microfísica de poder. Reorganizam os corpos todos os soldados de um batalhão, da respiração ao marchar. Ordem corporal, linearidade, sobriedade e uniformidade é o que se espera de um bom soldado. Afinal, uma vez com o corpo (também mente) docilizado, fica mais fácil de executar e não questionar nenhuma ordem recebida.

Nosso primeiro contato foi intermediado por uma psicóloga e uma assistente social que atuam por mais de dois anos na instituição. Com a sensação de vigilância, de constante avaliação ou julgamento, o trabalho foi-se modificando para que coubesse nas exigências da equipe. Aqui, me cabe conceituar termos implícitos no regime punitivo, e que percebi desconhecimento por parte das funcionárias. Recorro a Foucault para compreender as estruturas de punição, e, novamente me deparo com a problemática situada primordialmente no corpo dos detentos. Foucault (2008) salienta que, apesar de hoje em dia as medidas punitivas terem se alastrado ao caráter do castigo psicológico, o corpo segue sendo marcado pela vivência (até mesmo da violência emocional) carcerária:

\begin{abstract}
Mas podemos sem dúvida ressaltar esse tema geral de que, em nossas sociedades, os sistemas punitivos devem ser recolocados em uma certa "economia política" do corpo: ainda que não recorram a castigos violentos ou sangrentos, mesmo quando utilizam métodos "suaves" de trancar ou corrigir, é sempre do corpo que se trata - do corpo e de suas forças, da utilidade da docilidade delas, de sua repartição e de sua submissão. (FOUCAULT, 2008, p.25)
\end{abstract}

Se os direitos humanos já não permitem (ao menos não de forma explícita) torturas, o papel da ressocialização fica a cargo de regras criadas pela sociedade. O que me devolve ao que o sociólogo Becker coloca enquanto desvio e desviantes, outsiders, regras e seus criadores e executantes. "A concepção mais simples de desvio é essencialmente estatística, definindo como desviante tudo que varia excessivamente com relação à média [/ou ainda], uma consequência das reações de outros ao ato de uma pessoa (BECKER, 2008, p. 18-19).” O que tornará o outro desviante é então, para Becker, nosso 
próprio julgamento das ações (muitas vezes isoladas) do outro. Somos nós quem classificamos o outro, que está a margem de nós e fragilizado por nossos próprios preconceitos.

De volta às oficinas, os participantes foram selecionados a partir de crivo pessoal das funcionárias, considerado em primeira instância a desenvoltura (preferencialmente os mais tímidos) e por último o interesse dos jovens. Psicóloga e assistente social se dirigiram até os quartos de cinco jovens de poucas palavras, e quase imploraram suas presenças na oficina. Saí em desvantagem: a oficina de teatro acontecia durante as oficinas de futebol e ping-pong. Alguns dos rapazes preferiram as outras atividades, então trabalhei com os de fato interessados - ou que demonstraram a priori interesse. Segundo relatado por alguns dos jovens, “fazer teatro era melhor do que correr atrás de uma bola, ou ficar vendo uma bolinha quicar"4. Não criei resistência quanto à permanência dos rapazes na oficina. Trabalhei com no máximo seis adolescentes por aula.

A partir daí, iniciamos um círculo de apresentação, em que os jovens relataram estarem estudando entre o $9^{\circ}$ ano do ensino fundamental (o regime para o ensino básico adotado pela instituição é o EJA, já o médio é regular) e o $2^{\circ}$ ano do ensino médio. Dentre as profissões almejadas pelos participantes estão juízes, professores e indecisões. Idades: todos entre dezessete e dezenove anos. Todos brancos, e, presumo, por pura descrença na eficácia do sistema judiciário, pobres. Do contrário teriam advogados que os ajudariam a cumprir a medida em semiliberdade, ou até mesmo pagando serviços comunitários.

Apresentações feitas, o primeiro jogo consistia em caminhar pela sala, evitando caminhar em círculo, explorando direções e velocidades diferentes e passando uma bolinha de tênis para o colega. Ao passar, deveriam dizer seus nomes e contar em voz alta até trinta. Cada passe configurava um nome e um número. O jogo serviu para que se familiarizassem entre si, pois só se conheciam entre vistas e revistas. Após cumprirem a contagem, partimos para o que nos interessava: contato.

Instigava-me que pouco soubessem um do outro, que não conhecessem as histórias e motivos pelos quais estavam dividindo aquele espaço penal. Pensei, talvez equivocada ou adiantadamente, que ao realizarem jogos de contato físico, ampliariam o diálogo entre si e se interessariam em estabelecer relações para além da oficina. Notei, logo em seguida, através da resistência física dos jovens em tocar o corpo do colega

${ }^{4}$ Relato de um adolescente participante da oficina. 
(mesmo que nas costas) que os movimentos eram demasiado "íntimos" para eles, o que ocasionou certo desconforto no decorrer da aula.

Seguindo as propostas de Boal (2008), utilizamos o jogo João Bobo para estimular a confiança e a seguridade no grupo. Em trios, um colega fica no meio e se desloca em desequilíbrio para frente e para trás, sem dobrar os joelhos, enquanto os outros dois devem apoiá-lo, impedindo sua queda. Enquanto revezavam entre apoiado e apoiador, dois jovens não participaram do deslocamento por dificuldades físicas (um possuía uma bala alojada nas costas e outro havia operado recentemente o joelho). O jogo criou abertura para trabalharmos uma variação, ainda objetivando confiança de grupo. Desta vez em círculo, com os ombros próximos um do outro, um integrante por vez deixava seu corpo desequilibrar para trás, para que os dois integrantes de suas laterais o amparassem e impedissem sua queda. Neste, poucos experimentaram o desequilíbrio, mas se demonstraram atentos em acolher quem ousasse se entregar.

A proposta seguinte partiu da mesma configuração espacial, circular. Intitulado Nó Humano, o jogo estimula a mobilidade corporal. Desta vez, os participantes deveriam memorizar quem estava a sua esquerda e a sua direita na formação do círculo e caminhar pela sala. Dado momento, solicitei que parassem onde estavam na sala. Ali, devem localizar os colegas das laterais e, com o mínimo de locomoção possível, dar a mão correspondente á direção que estavam. Visei, com este jogo, dificultar suas mobilidades para que retomassem a formação original se movimentando de modo extracotidiano.

Percebendo os discretos olhares nos relógios das monitoras (que realizaram juntas todos os jogos propostos), decidi encerrar o encontro com uma massagem elementar: novamente em círculo, um colega centraliza-se enquanto os outros dão leves "soquinhos" pelo corpo do outro, simbolizando a terra; fazem movimentos de pinça com as mãos simbolizando o fogo; esfregam as mãos pelo corpo do outro para representar a água e sopram o corpo do colega para dar a entender o trabalho do ar. Neste exercício, me surpreendi com a postura de um dos participantes. O jovem solicitou que a psicóloga massageasse as pernas da outra mulher presente no jogo, alegando ser ele homem, e por isso, impossibilitado de tocar nas pernas de uma mulher. A colocação gerou reflexão e debate pós-oficina entre as monitoras e eu.

A respeito da participação vigilante das monitoras durante as oficinas, confesso, na primeira instância, sentir desconforto na condução das práticas. Acredito que tenha transpassado parte dele aos jovens, que ao realizar qualquer proposta que fosse, as olhavam esperando uma resposta de aprovação de seus atos. Sentia com se os exercícios 
fossem realizados por eles com o intuito de agradar as mulheres ali presentes. Ao longo dos encontros a impressão foi-se dissolvendo, mas timidamente.

Em avaliação feita junto das monitoras, nos foi solicitado dar atenção aos exercícios de contato físico. Ambas alegaram não se sentirem confortáveis com o toque dos rapazes, julgando ser melhor pensarmos em jogos que evitassem tais práticas. Os motivos do desconforto, não recebi com otimismo. Elas se colocam em lugar superior ao ocupado pelos garotos - é perceptível quando corrigem a fala dos jovens, questionam o uso que fazem de gírias e criticam o modo como se vestem, atitudes das funcionárias que presenciei durante a oficina. Logo, encostá-los era tarefa que exigia desprendimento do ego - atitude que elas não demonstraram disponibilidade ou interesse em realizar. Segundo as mesmas, suas relações se limitam ao cumprimento com as mãos, o que pretendiam manter por questões de segurança, e para não alimentar o imaginário dos meninos. Erotizam, psicóloga e assistente social, o que há de possibilidade ou potência até mesmo lúdica na prática teatral. Penso estar nelas, nas monitoras, a maior dificuldade em realizar trabalhos com menores infratores.

\section{Referências de cenas por trás dos muros da prisão: o cárcere e o Teatro em São Paulo}

O encontro com a obra e o trabalho de Vicente Concílio me chegou por indicação de professores do curso de Licenciatura em Teatro da UFSM, cientes do meu processo com menores infratores. Como incentivo de análise sobre a arte em ambientes carcerários, Concílio (2008), na obra Teatro e Prisão: dilemas da liberdade artística, relata trabalhos que realizou com presidiárias em regime fechado. Nele as mulheres contavam, em cena, os motivos pelos quais estavam presas, através das técnicas do Teatro do Oprimido, de Augusto Boal (1977). Também me utilizo de um artigo do autor, que contextualiza o trabalho com Teatro no cárcere em cenário nacional. Aqui, autores como "Frei Betto (Freire \& Betto, 1986), Maria Rita Freire Costa (Costa, 1983) e Ruth Escobar (Escobar, 1982; Fernandes, 1985) são exemplos da variedade e da vitalidade das práticas cênicas construídas no interior de instituições punitivas (CONCÍLIO, 2005, p.151)”.

Segundo o autor, após a apresentação de um espetáculo dirigido por Maria Rita Freire Costa em que duas presas fugiram, o trabalho com teatro passa a ser encarado pelo “corpo funcional dos presídios associado à subversão, ao desrespeito e à vadiagem (p. 152)." Após mais de dez anos de trabalhos teatrais em presídios, os projetos realizados nesse ambiente ganham novamente potência em 1995, com a montagem de O auto da 
compadecida, de Ariano Suassuna. A montagem repercute e é assistida até mesmo pelo dramaturgo.

A arte encontra fissuras na rigidez da penitenciária, e novamente Concílio me contempla quando diz que "é imprescindível atribuir ao teatro o caráter agregador e coletivo inerente a seu exercício. Daí o peso de suas conquistas em um presídio, instituição total que prima pela massificação no trato dos indivíduos a ele submetidos [...] (CONCÍLIO, 2005, p. 153).” Após o sucesso da primeira montagem, a segunda não deixou a desejar. Com O Rei e a Vela de Oswald de Andrade, recebem o convite de Zé Celso Martinez Corrêa para apresentarem no próprio Teatro Oficina, palco do grupo por mais de trinta anos. Lá,

\begin{abstract}
A apresentação obteve grande repercussão e garantiu quase o dobro da capacidade do teatro, com o público lotando os três andares do espaço que compõe a área que lhe é destinada [...]. Lá o público presenciou, além do espetáculo, parte do trato dispensado aos apenados, e que os muros da prisão escondem: os atores, ainda recebendo aplausos calorosos da platéia, foram algemados com brutalidade e, escoltados por dois policiais cada um, saíram correndo em direção ao porta-malas do camburão que os levaria ao presídio. (CONCÍLIO, 2005, p. 154)
\end{abstract}

É neste regime severo, de pouca ou nenhuma sensibilidade no que cerne o tratamento dado aos detentos, que notamos a necessidade do trabalho artístico. No que se refere a presença do público, Concílio relata a surpresa da plateia ao se deparar com um elenco composto por presidiários. Para ele, existe na experiência do espectador um vislumbre do potencial artístico, a partir do Teatro, em que denotam "a beleza e o prazer da fruição de uma arte de resistência, que derruba preconceitos e constrói novas conotações a essas vidas encarceradas (CONCÍLIO, 2005, p.157).”

Concílio recorre a Rocha (1999) em uma frase que, a meu ver, resume a postura com que a administração encara a relação com os menores infratores: "corrigir as pessoas sempre foi um objetivo ligado ao uso que se quer fazer delas (Rocha, 1999, apud Concílio, 2008, p. 20)." Como condutora de práticas teatrais, tendo feito visitas e trabalhado em poucas aulas, pude notar sem esforços quais eram os objetivos daquelas pessoas para com os detentos. Querem deles corpos rígidos e mentes aprisionadas pela obediência.

Ainda em Vicente se evidencia o descaso por parte da administração com as propostas artísticas. Em seus escritos, nota-se que a administração das penitenciárias causou cancelamento de projetos artísticos, interdição de salas de ensaio, corte de verbas destinadas às produções, proibição e exclusão de determinados detentos, entre outros dificuldades enfrentadas por ele, que a mim soaram como boicote às atividades propostas. 


\section{Considerações parciais: chegar ao fim, ou recomeçar?}

Ao repensar o lugar do Teatro (se é que há algum, se é que não são todos), percebemos os mesmos conflitos ao comparar ao Centro para Menores Infratores, Penitenciárias Femininas ou Penitenciárias de Segurança Máxima. Notamos que os maiores problemas não se concentram nas relações entre as e os detentos, nem nas dificuldades em se explicar propostas cênicas, ou na elaboração de cenas, de jogos ou exercícios teatrais: as administrações dos presídios são nossos maiores impasses dentro do cárcere.

Será então, que o objetivo destes locais, expostos no início do artigo, são mesmo incluir as e os detentos em práticas pedagógicas? Almejam mesmo proporcionar pensamento crítico - como dizem - aos detentos? Estarão mesmo preocupados na reinserção destas pessoas ao convívio social, para além do presídio?

Como fazer teatro, prática que exige a exposição sem amarras, a liberdade de jogar com personas e situações diversas, em espaços em que o controle é a regra geral? Como convocar o outro à exposição em um local tão árido e repressor? Enquanto promotora das práticas, aquela que busca preparar a aula de teatro como um presente, como articular propostas que respeitem as individualidades, interesses e identidades de pessoas que convivem diariamente com o comando repressor da vigilância?

Estes questionamentos permaneceram vivos em mim mesmo com o término do projeto vinculado ao CASE, e seguirão latentes impulsionando minhas práticas e pesquisas, até que em algum momento eu me surpreenda com a possibilidade de articulação e mobilização do contexto repressor para um contexto emancipador. Quem sabe essa modificação possa ter relação direta com meus modos de propor as práticas, com as possibilidades que eu, enquanto agente facilitadora de processos de ensinoaprendizagem em teatro, encontro como alguém que visita esses espaços sem efetivamente pertencer a eles. Encontrar fissuras dentro desse sistema, rígido e coercitivo, é encontrar a beleza e o potencial de mudança que, a meu ver, a arte da cena transborda.

\section{Referências}

BECKER, W. Outsiders: estudos de sociologia do desvio. Rio de Janeiro: Jorge Zahar. 2008. 
BOAL, A. Teatro do oprimido e outras poéticas políticas. $2^{\text {a }}$ Ed. Rio de Janeiro: Civilização Brasileira. 1977.

BOAL, A. Jogos para atores e não-atores. $11^{\text {a }}$ Ed. Rio de Janeiro: Civilização Brasileira

CONCILIO, V. Teatro e prisão: dilemas da liberdade artística. São Paulo: Editora Hucitec, 2008.

CONCÍLIO, V. (2005) de et. al. Teatro e prisão: dentro da cena e da cadeia. Sala Preta. São Paulo, v. 5, n. p. 151-158. Disponível em:

http://www.revistas.usp.br/salapreta/article/view/57273/60255 Acessado em: 05/19.

FOUCAULT, M. Vigiar e punir: nascimento da prisão. 35ª ed. Petrópolis, RJ: Vozes, 2008.

FREIRE, P. Pedagogia do oprimido. 17ª Ed. Rio de Janeiro: Paz e Terra. 1987.

FREIRE, P. Pedagogia da autonomia: saberes necessários à prática educativa. $54^{\mathrm{a}}$ Ed. Rio de Janeiro: Paz e Terra. 2016.

LARROSA, Jorge. Pedagogia Profana: danças, piruetas e mascaradas. $4^{\circ}$ ed. Belo Horizonte: Autêntica, 2004.

\section{RECEBIDO EM: 26/05/2019 | APROVADO EM: 31/10/2019}

